OPEN ACCESS

Edited by: Hongyan Ning,

Northwestern University, United States

Reviewed by: Norbert Stefan,

University of Tübingen, Germany

I-Shiang Tzeng,

National Taipei University, Taiwan Yi-Cheng Hou,

Taipei Tzu Chi Hospital, Taiwan

${ }^{*}$ Correspondence:

Jau-Yuan Chen welins@cgmh.org.tw

Specialty section

This article was submitted to Coronary Artery Disease

a section of the journal Frontiers in Cardiovascular Medicine

Received: 28 October 2021 Accepted: 10 February 2022 Published: 03 March 2022

Citation:

Tsou M-T and Chen J-Y (2022)

Gender-Based Association of Coronary Artery Calcification and

Framingham Risk Score With

Non-alcoholic Fatty Liver Disease and Abdominal Obesity in Taiwanese Adults, a Cross-Sectional Study. Front. Cardiovasc. Med. 9:803967. doi: 10.3389/fcvm.2022.803967

\section{Gender-Based Association of Coronary Artery Calcification and Framingham Risk Score With Non-alcoholic Fatty Liver Disease and Abdominal Obesity in Taiwanese Adults, a Cross-Sectional Study}

\author{
Meng-Ting Tsou ${ }^{1,2,3}$ and Jau-Yuan Chen ${ }^{4,5 *}$ \\ ${ }^{1}$ Department of Family Medicine, Mackay Memorial Hospital, Taipei City, Taiwan, ${ }^{2}$ Department of Occupation Medicine, \\ Mackay Memorial Hospital, Taipei City, Taiwan, ${ }^{3}$ Department of Mackay Junior College of Medicine, Nursing, and \\ Management, New Taipei City, Taiwan, ${ }^{4}$ Department of Family Medicine, Chang-Gung Memorial Hospital, Linkou Branch, \\ Linkou, Taiwan, ${ }^{5}$ Department of Medicine, College of Medicine, Chang Gung University, Taoyuan, Taiwan
}

Background: It is not certain whether non-alcoholic fatty liver disease (NAFLD) or abdominal obesity $(\mathrm{AO})$ has stronger associations with atherosclerosis and coronary artery disease (CAD) risk across different genders. The purpose of this study was to determine the gender-based association of NAFLD and AO with subclinical atherosclerosis represented by coronary artery calcification (CAC) and CAD risk by Framingham risk score (FRS).

Methods: A total of 1,655 participants in a health-screening program (mean age: 49.44 years; males: $70.33 \%$ ) were enrolled for analysis. Fatty liver and coronary artery calcium score (CACS) were measured via ultrasonography (US) and multi-detector computed tomography (MDCT). The presence of CAC was defined as having a CACS $>0$, intermediate to high $C A D$ risk was defined as $F R S \geq 10 \%$, while the presence of $A O$ was defined as having a waist circumference (WC) of $\geq 90 \mathrm{~cm}$ for men and $\geq 80 \mathrm{~cm}$ for women. Participants were categorized into four groups depending on the presence or absence of NAFLD and/or AO.

Results: The percentage of subjects with CACS $>0$ was highest in the AO-only group (overall: 42.6\%; men: 48.4\%; women: $35.8 \%$ ); and $\mathrm{FRS} \geq 10 \%$ was highest in the group with both abnormalities (overall: $50.3 \% \%$; men: $57.3 \%$; women: $32.4 \%$ ). After adjustment factors, the odds ratio (OR) for CAC and FRS was the highest in the group with both abnormalities [men: 1.61 (1.13-2.30) for CACS $>0$ and 5.86 (3.37-10.20) for FRS $\geq 10 \%$; women: $2.17(1.13-4.16)$ for CACS $>0$ and 6.31 (2.08-19.10) for FRS $\geq 10 \%]$. In men, the OR of NAFLD was higher than that of $\mathrm{AO}[1.37(1.03-1.83)$ vs. $1.35(1.02-1.79)$ for CACS $>0,3.26(2.13-4.98)$ vs. 2.97 (1.91-4.62) for FRS $\geq 10 \%]$. However, women with AO consistently showed increased OR for CACS $>0$ [1.87 (1.11-3.16)] and FRS $\geq 10 \%$ [4.77 (2.01-11.34)]. 
Conclusion: The degree of association of NAFLD and AO with CAC and FRS depends on the gender. NAFLD is more closely associated with CACS $>0$ and FRS $\geq 10 \%$ in men and $A O$ in women, respectively. NAFLD and $A O$ could be considered independent determinants of CAC and FRS by gender.

\section{Keywords: coronary artery calcification, non-alcoholic fatty liver disease, abdominal obesity, Framingham risk score, Taiwan}

\section{INTRODUCTION}

Coronary artery disease (CAD) caused by atherosclerosis is the leading cause of morbidity and mortality worldwide, thus becoming one of the most serious global health issues (1). In asymptomatic individuals, early detection of subclinical atherosclerosis is necessary to prevent or delay its progression to overt CAD. Coronary artery calcium score (CACS), a useful marker of subclinical atherosclerosis detected by multi-detector computed tomography (MDCT), is frequently used to predict and prevent overt CAD (2). The close correlations of CACS with cardiovascular events or obesity have already been noted in a previous study (3). The Framingham risk score (FRS) provides an estimate of CAD risk for the general population (4-6). As mentioned in previous studies, both FRS and CACS were independently associated with subclinical atherosclerosis in asymptomatic subjects with low to intermediate cardiovascular risk $(5,6)$.

Obesity is regarded as an independent risk factor for atherosclerosis and $\operatorname{CAD}(7,8)$, and is closely associated with other CAD risk factors such as hypertension (HTN), diabetes mellitus (DM), and dyslipidemia $(9,10)$. Previous studies have focused on abdominal and visceral obesity (localized distribution of body fat rather than total body fat), which have since been considered major risk factors for CAD (11-14). From the recent study on severe acute respiratory coronavirus syndrome 2 (SARS$\mathrm{CoV}-2$ ), it was found that obesity (specifically visceral obesity) and characteristics of impaired metabolic health such as DM, HTN and subclinical inflammation, also emerged as important determinants of severe coronavirus disease 2019 (COVID19) (15). Waist circumference (WC) and hip circumference (HC) are two of the easy ways to measure abdominal obesity (AO) $(16,17)$. Actually, WC allows visceral adiposity to be differentiated from total obesity, considers fat distribution, correlates well with abdominal imaging, and is more predictive of coronary artery calcification (CAC) than other anthropometric indicators $(16,18,19)$.

Non-alcoholic fatty liver disease (NAFLD) has become a common health problem with a prevalence of about $20-30 \%$ in Western population (20); among extensive population-based surveys in Asia, the prevalence rates of NAFLD were between 2.04 and $52 \%(21,22)$. Taiwan has a prevalence of $11.5-$ $52 \%$ (23). NAFLD is a manifestation of metabolic syndrome (MetS), obesity, and insulin resistance (IR) in the liver $(24,25)$. Previous studies have shown that NAFLD could be considered a cardiovascular risk factor by advancing the progress of subclinical atherosclerosis or cardiovascular disease (26-28). However, it is unclear whether there is gender-based differences in the association of NAFLD or WC with atherosclerosis and CAD risk. Therefore, risk assessment of NAFLD and WC by gender is important to apply different therapeutic approaches to reduce atherosclerosis and reduce the risk of CAD.

A recent study suggests that NAFLD is more closely related with CAC than AO assessed by waist-to-hip ratio (WHR) (29). In addition, whether a cross-sectional study or a cohort study, they reported a predicted higher 10-year CAD risk as determined by the FRS in patients with NAFLD $(30,31)$. The purpose of this study is to determine gender differences in the association of NAFLD and AO and the risk of subclinical atherosclerosis and CAD in an apparently healthy Taiwanese population. For this purpose, we evaluated the risk of subclinical atherosclerosis and $\mathrm{CAD}$ in subjects divided into four groups according to the presence/absence of NAFLD diagnosed by US and the presence/absence of AO measured via WC status in men and women. We analyzed CACS and FRS in these four groups to determine the association of NAFLD and AO with risk of subclinical atherosclerosis and CAD in men and women.

\section{METHOD}

\section{Study Design and Study Population}

In this cross-sectional study, which was performed retrospectively from 2005 to $2009,2,249$ adult subjects participated. They were screened for cardiovascular health at a territory medical center in Taipei, where they were subjected to MDCT to screen their coronary calcium levels. Subjects who had full details about abdominal ultrasound (US), height, weight, body mass index (BMI), waist circumference (WC), information on the metabolic component were selected for the study. All the subjects had a self-reported history of acute ischemic heart disease, angina pectoris or any congenital heart disease. Subjects who didn't fulfill these two selection criteria were excluded. Further subjects who consumed alcohol $\geq 20$ $\mathrm{g} /$ day, history of viral hepatitis or chronic hepatic disease, consumption of hepatoxicity medicine (like statins, estrogen, tamoxifen, diltiazem, and valproate) were all excluded from the study (Figure 1). After applying the selection criteria 594 subjects were excluded and finally, 1,655 (age: $49.5 \pm 9.8$ years; $70.3 \%$ male) were selected for the study.

A standardized questionnaire was used to screen the baseline characteristics, medical history and other intricate information open through physical examination. We considered a systolic blood pressure (SBP) of more than $140 \mathrm{mmHg}$, and/or diastolic blood pressure (DBP) of more than $90 \mathrm{mmHg}$ as hypertensive. 


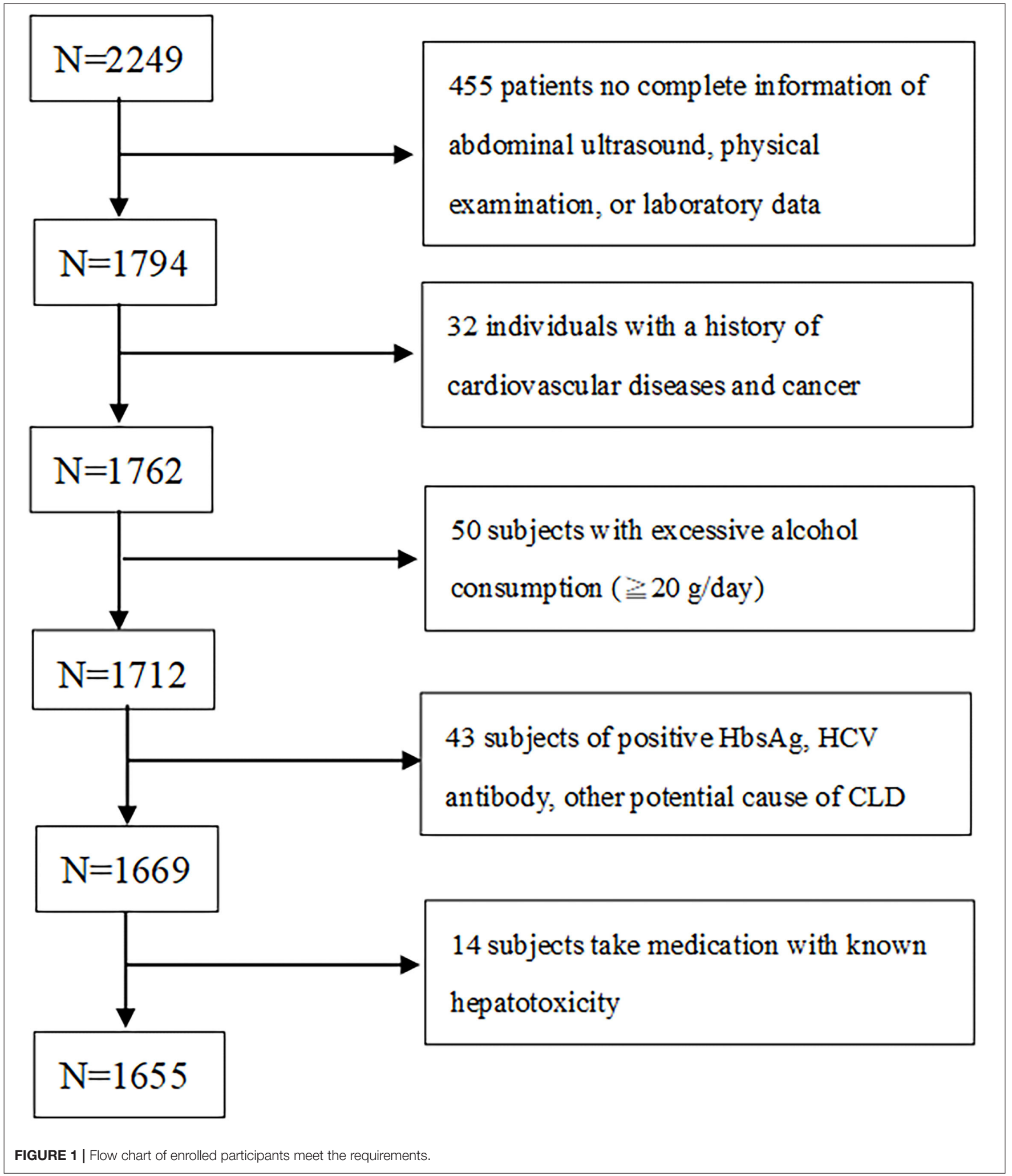

Subjects who were already diagnosed as hypertensive and under medication were also considered. Fasting Glucose (FG) level of $126 \mathrm{mg} / \mathrm{dL}$ or consumption of oral hypoglycemic agent/insulin were considered diabetic in the study. Subjects who had total cholesterol (TC) levels more than $200 \mathrm{mg} / \mathrm{dL}$ or triglycerides (TG) more than $150 \mathrm{mg} / \mathrm{dL}$ or under medication for dyslipidemia 
were considered dyslipidemia in this study. A part of this research had been published already in 2012 (32).

\section{Anthropometric and Laboratory Measurement}

At the baseline, a complete anthropometric analysis was carried out where height, weight, BMI and WC were recorded. WC was assessed following normal expiration from the midpoint between the 12th rib and the iliac crest. A standard sphygmomanometer was used to define resting blood pressure. All the anthropometric values for the study were collected at a laboratory center by well-trained nurses who were blinded to the study participants.

Acquisition and analysis - Hitachi 7170 Automatic Analyzer (Hitachi Corp., Hitachinaka Ibaraki, Japan) was used for measuring FG (hexokinase method) following $12 \mathrm{~h}$ of fasting before morning $10 \mathrm{AM}$. Along with this complete lipid profiles [including TC, TGL, low and high-density lipoprotein (LDL, HDL); homogenous enzymatic colorimetric assay], aspartate aminotransferase (AST), alanine aminotransferase (ALT), hepatitis B surface antigen, and an antibody to hepatitis $\mathrm{C}$ virus were also assessed using standard laboratory procedures.

\section{Diagnosis of NAFLD and Abdominal Obesity}

Fatty liver was diagnosed using abdominal US (Acuson, Sequoia 512, Siemens, Mountain View, CA) performed by gastroenterologists richly experienced who were blinded to the laboratory and clinical details of the subjects at the time of the procedure. If different results were found, a third doctor was asked to perform the test while blinded to test results and patient information. Asia-Pacific Working Party on NAFLD and Chinese Association for the Study of Liver Disease (CASLD) guidelines were adopted. The presence of at least two of the following factors was considered fatty liver; diffusely enlarged liver near field ultrasound echo ("bright liver"); liver echo greater than kidney; vascular blurring and the gradual attenuation of far-field ultrasound echo $(33,34)$.

Subjects were rendered $\mathrm{AO}$ if their waist circumference $\geq 90 \mathrm{~cm}$ among men and $80 \mathrm{~cm}$ among women in accordance to the classification of the National Cholesterol Education Panel of the National Treatment Program for Adults III (NCEP-ATP III) Taiwanese population for $\mathrm{AO}(35,36)$.

\section{CAC Measurements}

A 16-slice MDCT scanner (Sensation 16; Siemens Medical Solutions, Forchheim, Germany) with $16-\times 0.75-\mathrm{mm}$ collimation, rotation time of $420 \mathrm{~ms}$, and tube voltage of $120 \mathrm{kV}$ was used to measure the calcification of all coronary arteries using a dedicated offline workstation (Aquarius 3D Workstation; TeraRecon, San Mateo, CA, USA). A site with a density $>130 \mathrm{HU}$ and lasting at least six pixels were defined as a "coronary calcified lesion." Distinct atherosclerosis that was clinically important was defined by the presence of CAC; the burden of atherosclerosis that was defined by CAC score (CACS) which was semi-quantitatively measured using the Agatston score by multiplying every lesion (area) by a weighted CT attenuation score of the lesion (Figure 2) (32).

\section{FRS Score Calculation and Risk Category}

The FRS analysis after considering the subjects age, gender, TC, HDL, SBP, treatment for hypertension and cigarette smoking (36) categorized them as "low" ( $<10 \% 10$-year risk), "intermediate" (10-20\% risk) or "high" risk ( $\geqq 20 \%$ risk).

\section{Ethics}

Ethical clearance for the study (done per the Helsinki Declaration of 1975) was provided by the Human Research Ethics Committee of Mackay Memorial Hospital (project research number 18MMHIS137, 15 Oct 2018). The subjects were deidentified for data analysis and didn't give any informed consent as this was a retrospective study.

\section{Statistical Analysis}

The baseline values were presented as mean \pm SD for continuous data and percentile value for categorical data. If the normality assumption was violated based Shapiro-Wilk test, we use the non-parametric method instead. Non-parametric comparisons of the medians between the groups were performed using Kruskal-Wallis $\mathrm{H}$ test. One-way analysis of variance was used to analyze parametric data and chi-square or Fisher's exact test was used for non-parametric data analysis. Because this study aimed to further realize the difference between the two groups, separately, the data was mainly analyzed with post-hoc analysis with Bonferroni correction.

As CACS values were extremely skewed, logarithmized CACS +1 was used for the comparison between the groups. CACS and FRS were dichotomized as the presence of CACS $>0$ vs. absence of CACS $=0$ and FRS $\geq 10$ vs. FRS $<10 \%$ for binary logistic regression analysis. Multivariate logistic regression analyses were performed to analyze the relationship among groups with CACS $>0$ and FRS $\geq 10 \%$ while controlling for potential confounding variables included in the model. Covariates in the multivariable model, chosen for clinical importance as well as statistical significance included age, BMI, HTN, DM, hyperlipidemia, cigarette smoking, alcohol drinking, and exercise. SPSS (IBM Corp., Armonk, NY, USA) was used to compute the statistic for the study. Odds ratios (ORs) was obtained and a significance level was fixed at $p<0.05$ at $95 \%$ confidence intervals (CIs).

\section{RESULTS}

\section{The General Characteristics of Study Participants by Gender}

A total of 1,655 participants, including 1,164 men (70.3\%, mean age $48.67 \pm 9.61$ years) and 491 women $(29.7 \%, 51.26$ \pm 9.88 years) were classified into four groups according to the presence/absence of NAFLD and AO (Table 1) as follows: (1) subjects without either abnormality (men, $n=347,29.8 \%$; women, $n=198,40.4 \%$ ); (2) subjects with AO only (men, $n=62,5.3 \%$; women, $n=53,10.8 \%$ ); (3) subjects with NAFLD only (men, $n=404,24.7 \%$; women, $n=101,20.6 \%$ ); and (4) subjects with both abnormalities (men, $351,30.2 \%$; women, $n=$ $139,30.2 \%)$. 


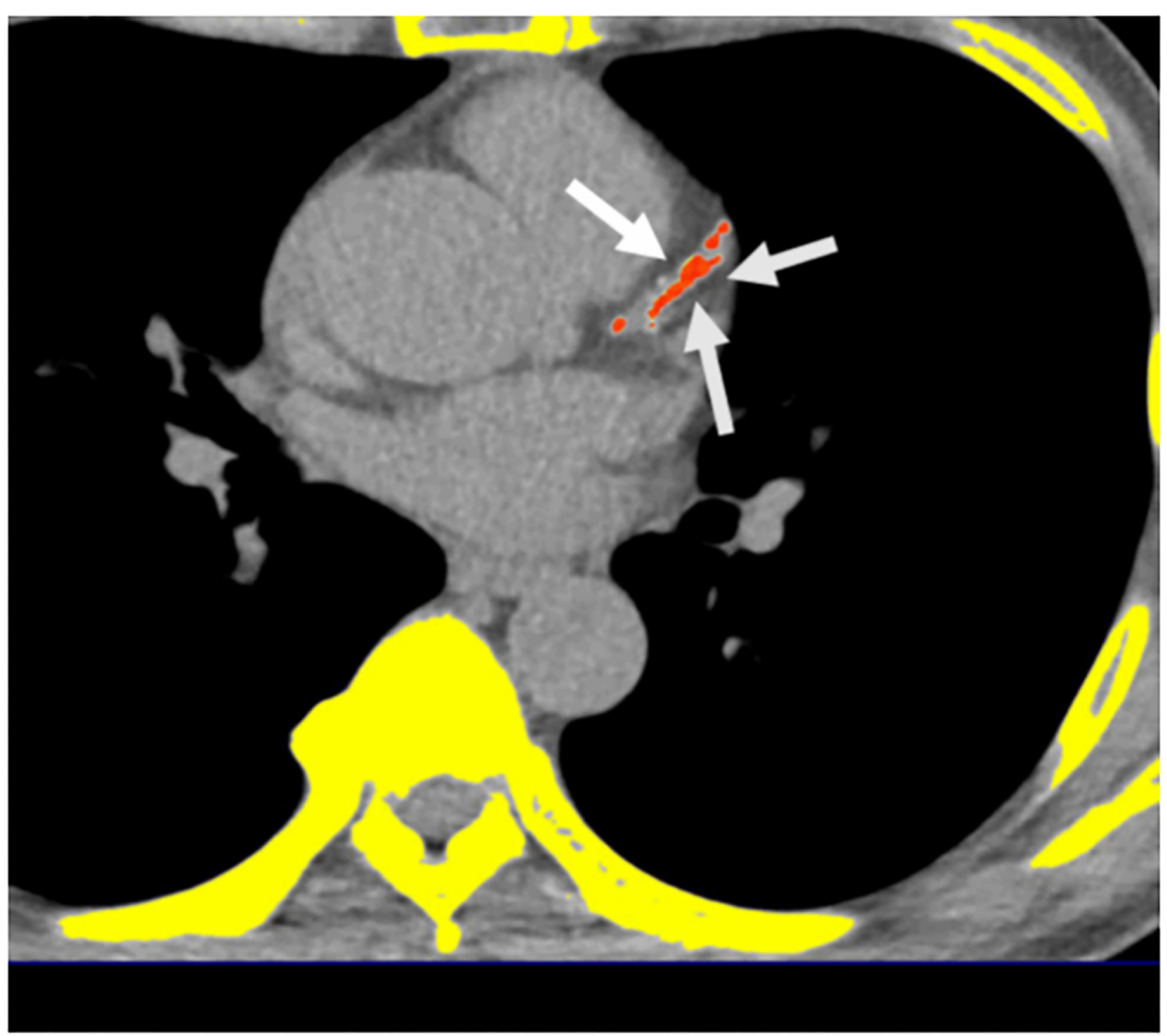

FIGURE 2 | Multidetector computed tomography (MDCT) demonstrated the quantification of CACS. Semi-automatic quantification of CACS burden using Agatston scoring. *Orange color regions indicate visceral fat tissue. White arrows indicate coronary calcification lesions.

\section{Comparison of Factors Between Groups According to NAFLD and AO Status}

Comparison of factors between groups revealed that the AO-only group was the oldest, while the worst metabolic factors were found in the group with both abnormalities (Table 1). By gender, metabolic factors, especially lipid profile, were worse in the NAFLD-only group than in the AOonly group. The mean WC for the entire population was $84.45 \pm 10.07 \mathrm{~cm} ; \mathrm{AO}$ subjects were generally more obese with higher mean BMI compared to those with NAFLD in both genders (Table 1). The group with both abnormalities had the highest proportion of subjects with abnormal liver function tests, DM, HTN, and dyslipidemia. The proportion of subjects with high ALT, DM, HTN, and dyslipidemia was higher in the AO-only group than in the NAFLDonly group. Furthermore, subjects with NAFLD tended to exercise less than subjects without NAFLD among the women (Table 1).

\section{Comparison of FRS in Four Groups by NAFLD and AO Status}

Among the total population, $33.8 \%$ had intermediate to high risk (FRS $\geq 10 \%$ ) (men: $41.2 \%$, women: $16.3 \%$ ). The proportion of subjects with intermediate to high risk was highest in the group with both abnormalities and lowest in the group without either abnormality (overall: 50.3 vs. $21.0 \%$; men: 57.3 vs. $30.5 \%$; women: 32.4 vs. $4.0 \%$ ) (Table 1 ).

Among all the participants, 995 (60.1\%) had NAFLD, while $605(36.6 \%)$ had AO. The prevalence of AO increased from $28.6 \%$ $(n=311)$ in subjects with low risk to $47.8 \%(n=172)$ in subjects with intermediate risk and 60.0\% $(n=120)$ in subjects with high risk (Figure 3A). The same trend was found in men $(n=177$, $26.1 \% ; n=128,42.8 \%$; and $n=106,58.6 \%$, respectively) and women $(n=134,32.7 \% ; n=44,72.1 \%$; and $n=14,73.7 \%$, respectively). Subjects with intermediate risk had the highest prevalence of NAFLD compared with the other groups; this was statistically significant in the overall population and in different 
TABLE 1 | The general characteristics of study participants by gender.

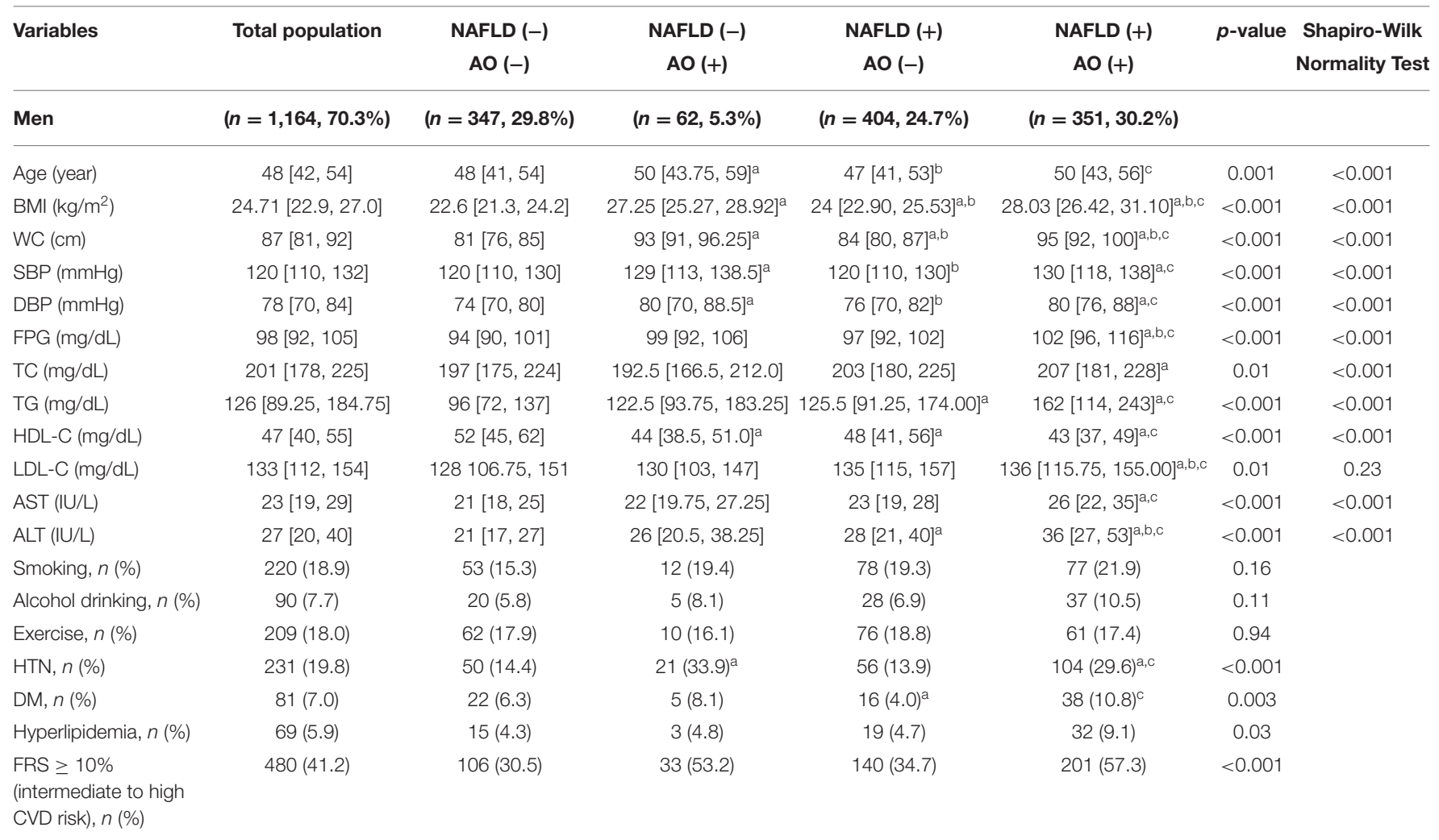

\begin{tabular}{|c|c|c|c|c|c|c|c|}
\hline Women & $(n=491,29.7 \%)$ & $(n=198,40.4 \%)$ & $(n=53,10.8 \%)$ & $(n=101,20.6 \%)$ & $(n=139,30.2 \%)$ & & \\
\hline Age (year) & $52[45,57]$ & $48.5[41,55]$ & $58[50.5,64.0]^{\mathrm{a}}$ & $49[43,56]^{\mathrm{b}}$ & $54[49,60]^{a, c}$ & $<0.001$ & 0.045 \\
\hline $\mathrm{BMI}\left(\mathrm{kg} / \mathrm{m}^{2}\right)$ & $22.90[20.92,25.43]$ & $20.8[19.6,22.2]$ & $24.41[23.0,26.2]^{\mathrm{a}}$ & $22.87[21.5,24.0]^{a, b}$ & $26.48[24.8,28.9]^{a, b, c}$ & $<0.001$ & $<0.001$ \\
\hline WC (cm) & $77[72,84]$ & $71[68,75]$ & $84[81,89]^{\mathrm{a}}$ & $75[72,78]^{a, b}$ & $87[82,93]^{a, b, c}$ & $<0.001$ & $<0.001$ \\
\hline $\mathrm{SBP}(\mathrm{mmHg})$ & $118[108,130]$ & $110[102,122]$ & $124[110,132]^{a}$ & $116[108,130]$ & $122[112,138]^{\mathrm{a}, \mathrm{c}}$ & $<0.001$ & $<0.001$ \\
\hline $\mathrm{DBP}(\mathrm{mmHg})$ & $72[68,80]$ & $70[64,75]$ & $74[70,82]^{a}$ & $70[67,80]^{\mathrm{a}}$ & $80[70,82]^{a, c}$ & $<0.001$ & $<0.001$ \\
\hline $\mathrm{TG}(\mathrm{mg} / \mathrm{dL})$ & $94[67,137]$ & $75.5[61,101]$ & $89[73,123]$ & $98[76,138.5]^{a}$ & $142[102,190]^{a, b, c}$ & $<0.001$ & $<0.001$ \\
\hline HDL-C (mg/dL) & $60[51,69]$ & $66[56,76]$ & $61[53,68]^{\mathrm{a}}$ & $57[49,65.5]^{\mathrm{a}}$ & $55[45,62]^{a, b}$ & $<0.001$ & $<0.001$ \\
\hline LDL-C (mg/dL) & $124[102,150]$ & $114[95.5,137.5]$ & $124[104.5,149.5]$ & $128[103.5,150.5]^{a}$ & $136[111,167]^{\mathrm{a}}$ & $<0.001$ & $<0.001$ \\
\hline AST (IU/L) & $21[17,25]$ & $19[17,23]$ & $21[17,25]$ & $21[18,25]$ & $22[19,28]^{a}$ & $<0.001$ & $<0.001$ \\
\hline ALT (IU/L) & $19[14,25]$ & $16[13,21]$ & $18[14,25]$ & $20[14,24]$ & $24[17,34]^{a, b, c}$ & $<0.001$ & $<0.001$ \\
\hline HTN, $n(\%)$ & 78 (15.9) & $13(6.6)$ & $15(28.3)^{\mathrm{a}}$ & $14(13.9)$ & $36(25.9)^{\mathrm{a}}$ & $<0.001$ & \\
\hline $\mathrm{DM}, n(\%)$ & $29(5.9)$ & $4(2.0)$ & $4(7.5)$ & $6(5.9)$ & $15(10.8)^{\mathrm{a}}$ & 0.01 & \\
\hline Hyperlipidemia, $n$ (\%) & 31 (6.3\%) & $4(2.0)$ & $5(9.4)$ & $7(6.9)$ & $15(10.8)^{\mathrm{a}}$ & 0.01 & \\
\hline $\begin{array}{l}\text { FRS } \geq 10 \% \\
\text { (intermediate to high } \\
\text { CVD risk), } n(\%)\end{array}$ & $80(16.3)$ & $8(4.0)$ & $13(24.5)$ & 14 (13.9) & 45 (32.4) & $<0.001$ & \\
\hline
\end{tabular}

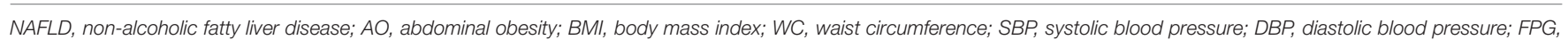

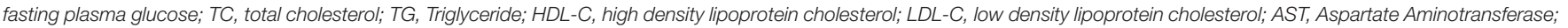
ALT, Alanine Aminotransferase; HTN, hypertension; DM, diabetes mellitus; CACS, coronary artery calcium score; FRS, Framingham risk score.

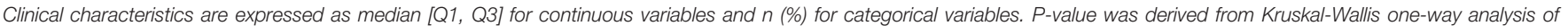
variance (one-way ANOVA) for continuous variables and categorical variables were expressed as percentages and compared with the $x^{2}$ test or Fisher's exact test.

${ }^{a} p<0.05$ vs. NAFLD (-) AO (-).

${ }^{b} p<0.05$ vs. NAFLD (-) AO (+).

${ }^{c} p<0.05$ vs. NAFLD (+) AO (-) in the Bonferroni post-hoc comparisons. 
A

$\begin{array}{ll}\text { a. Total } & \\ 90 \% & \mathrm{p}<0.001 \text { for in NAFLD }(+) \\ 80 \% & \mathrm{p}<0.001 \text { for in } \mathrm{AO}(+)\end{array}$

$72.5 \%$

$70 \%$

$60 \%$

$50 \%$

$40 \%$

$30 \%$

$20 \%$

$10 \%$

$0 \%$

b. Men

$90 \%$

$80 \%$

$70 \%$

$60 \%$

$50 \%$

$40 \%$

$30 \%$

$20 \%$

$10 \%$

$0 \%$

c. Wome

$80 \%$

$70 \%$

$60 \%$

$50 \%$

$40 \%$

$30 \%$

$20 \%$

$10 \%$

$0 \%$

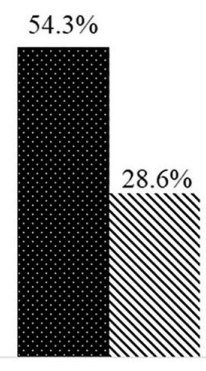

Low risk

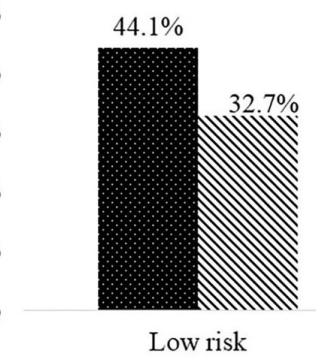

Low risk

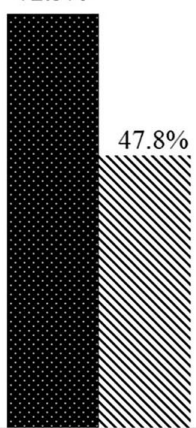

Intermediate

Framingham risk score

- NAFLD $(+)$ s $\mathrm{AO}(+)$

$\mathrm{p}=0.001$ for in NAFLD $(+)$

$\mathrm{p}<0.001$ for in $\mathrm{AO}(+)$

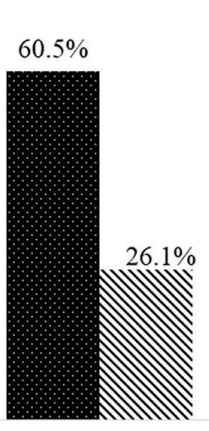

Low risk

$\mathrm{p}<0.001$ for in NAFLD $(+)$

$\mathrm{p}<0.001$ for in $\mathrm{AO}(+)$

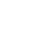

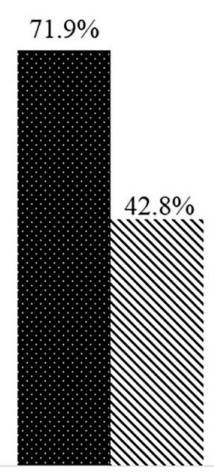

Intermediate

Framingham risk score

घAFLD $(+)$ NAO (+)

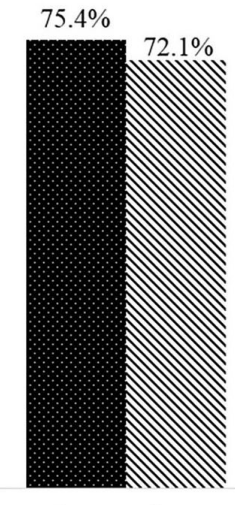

Intermediate

Framingham risk score

NAFLD $(+)$ NAO $(+)$

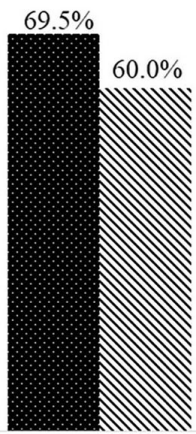

High risk 
B

a. Total

$90 \% \quad \mathrm{p}=0.001$ for chi-square test in NAFLD

$80 \% \quad \mathrm{p}=<0.001$ for chi-square test in $\mathrm{AO}$

$70 \%$

$60 \%$

$50 \%$

$40 \%$

$30 \%$

$20 \%$

$10 \%$

$0 \%$

b. Men

$90 \% \quad \mathrm{p}=0.11$ for chi-square test in NAFLD

$80 \%$

$70 \%$

$60 \%$

$50 \%$

$40 \%$

$30 \%$

$20 \%$

$10 \%$

$0 \%$ $\mathrm{p}=<0.001$ for chi-square test in $\mathrm{AO}$

\section{Coronary artery calcium score}

$\mathrm{CACS}=0$
$67.9 \%$

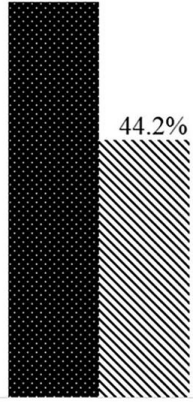

$0<\mathrm{CACS} \leq 100$

NAFLD $(+) \quad$ AO (+)

$69.5 \%$

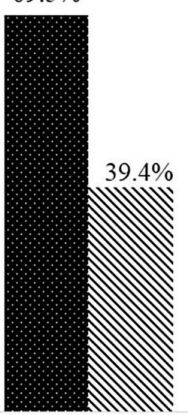

$0<\mathrm{CACS} \leq 100$

$63.3 \%$

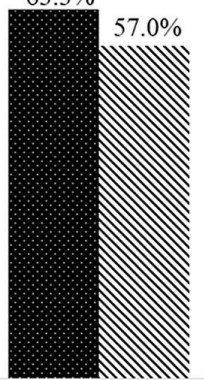

$\mathrm{CACS}>100$
$>100$ 
TABLE 2 | Comparison of coronary artery calcium score among the four groups divided by non-alcoholic fatty liver disease and abdominal obesity status.

\begin{tabular}{|c|c|c|c|c|c|c|}
\hline Variables & Total population & $\begin{array}{c}\text { NAFLD (-) } \\
\text { AO (-) } \\
(n=545)\end{array}$ & $\begin{array}{c}\text { NAFLD (-) } \\
\text { AO (+) } \\
(n=115)\end{array}$ & $\begin{array}{c}\text { NAFLD (+) } \\
\text { AO (-) } \\
(n=505)\end{array}$ & $\begin{array}{c}\text { NAFLD (+) } \\
\text { AO (+) } \\
(n=490)\end{array}$ & $p$-value \\
\hline Mean Ln (CACS+1) & $1.02 \pm 1.84$ & $0.70 \pm 1.58$ & $1.59 \pm 2.21^{a}$ & $0.87 \pm 1.65^{\mathrm{b}}$ & $1.39 \pm 2.08^{a, c}$ & $<0.001$ \\
\hline $\begin{array}{l}\text { Age-adjusted } \\
\text { mean Ln }(\mathrm{CACS}+1)\end{array}$ & $1.02 \pm 0.73$ & $0.93 \pm 0.73$ & $1.37 \pm 0.82^{\mathrm{a}}$ & $0.91 \pm 0.65^{\mathrm{b}}$ & $1.15 \pm 0.74^{\mathrm{a}, \mathrm{b}, \mathrm{c}}$ & $<0.001$ \\
\hline $\begin{array}{l}\text { Age and sex adjusted } \\
\text { mean } \operatorname{Ln}(C A C S+1)\end{array}$ & $1.02 \pm 0.79$ & $0.87 \pm 0.83$ & $1.28 \pm 0.85^{\mathrm{a}}$ & $0.97 \pm 0.72^{b}$ & $1.16 \pm 0.78^{a, c}$ & $<0.001$ \\
\hline CACS > $0, n(\%)$ & $508(30.7 \%)$ & $120(22.0 \%)$ & $49(42.6 \%)^{a}$ & $147(29.1 \%)^{b}$ & $19(39.2 \%)^{a, c}$ & $<0.001$ \\
\hline Men & $(n=1,164)$ & $(n=347)$ & $(n=62)$ & $(n=404)$ & $(n=351)$ & \\
\hline Mean Ln (CACS+1) & $1.16 \pm 1.94$ & $0.91 \pm 1.77$ & $1.79 \pm 2.32^{a}$ & $0.96 \pm 1.71^{b}$ & $1.54 \pm 2.18^{a, c}$ & $<0.001$ \\
\hline $\begin{array}{l}\text { Age-adjusted mean Ln } \\
(\mathrm{CACS}+1)\end{array}$ & $0.96 \pm 0.72$ & $0.92 \pm 0.74$ & $1.20 \pm 0.80^{a}$ & $0.88 \pm 0.64^{b}$ & $1.05 \pm 0.74^{c}$ & $<0.001$ \\
\hline $\begin{array}{l}\text { Age and sex adjusted } \\
\text { mean } \operatorname{Ln}(C A C S+1)\end{array}$ & $1.16 \pm 0.76$ & $1.12 \pm 0.78$ & $1.42 \pm 0.84^{a}$ & $1.08 \pm 0.68^{b}$ & $1.26 \pm 0.78^{c}$ & $<0.001$ \\
\hline CACS > 0, $n(\%)$ & 408 (35.1\%) & 98 (28.2\%) & $30(48.4 \%)^{\mathrm{a}}$ & $131(32.4 \%)^{b}$ & $149(42.5 \%)^{a, c}$ & $<0.001$ \\
\hline Women & $(n=491)$ & $(n=198)$ & $(n=53)$ & $(n=101)$ & $(n=139)$ & \\
\hline Mean Ln (CACS+1) & $0.67 \pm 1.52$ & $0.34 \pm 1.10$ & $1.35 \pm 2.08^{\mathrm{a}}$ & $0.51 \pm 1.35^{\mathrm{b}}$ & $1.00 \pm 1.74^{\mathrm{a}}$ & $<0.001$ \\
\hline $\begin{array}{l}\text { Age-adjusted mean Ln } \\
(\mathrm{CACS}+1)\end{array}$ & $1.15 \pm 0.74$ & $0.94 \pm 0.70$ & $1.58 \pm 0.81^{a}$ & $1.04 \pm 0.68^{b}$ & $1.38 \pm 0.68^{a, c}$ & $<0.001$ \\
\hline $\begin{array}{l}\text { Age and sex adjusted } \\
\text { mean } \operatorname{Ln}(C A C S+1)\end{array}$ & $0.67 \pm 0.78$ & $0.45 \pm 0.74$ & $1.12 \pm 0.85^{a}$ & $0.55 \pm 0.71^{b}$ & $0.91 \pm 0.72^{a, c}$ & $<0.001$ \\
\hline CACS >0, n (\%) & 100 (20.4\%) & $22(11.1 \%)$ & $19(35.8 \%)^{a}$ & $16(15.8 \%)^{b}$ & $43(30.9 \%)^{a, c}$ & $<0.001$ \\
\hline
\end{tabular}

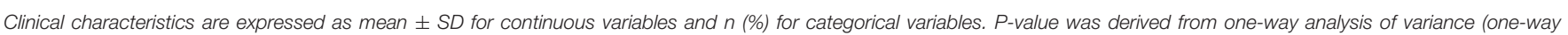
ANOVA) for continuous variables and categorical variables were expressed as percentages and compared with the $x^{2}$ test.

${ }^{a} p<0.05$ vs. NAFLD (-) AO (-).

${ }^{b} p<0.05$ vs. NAFLD (-) AO (+).

${ }^{c} p<0.05$ vs. NAFLD (+) AO (-) in the Bonferroni post-hoc comparisons. Abbreviations as list in Table 1.

gender (total, men, women: $172,72.5 \% ; 215,71.9 \% ; 44,75.4 \%$ ) (Figure 3A).

\section{Comparison of CACS in Four Groups by NAFLD and AO Status}

Among the total population, 30.7\% had CACS > 0 (men: $35.1 \%$, women: $20.4 \%$ ), and the mean $\ln ($ CACS +1 ) was 1.02 (men: 1.16; women: 0.67) (Table 2). When comparing the mean, age-adjusted, or age/sex-adjusted $\ln (\mathrm{CACS}+1)$ across groups, the values were the highest in the AO-only group and the lowest in the group without either abnormality (Table 2). The proportion of subjects with CAC was highest in the AO-only group and lowest in the group without either abnormality (overall: 42.6 vs. $22.0 \%$; men: 48.4 vs. $28.2 \%$; women: 35.8 vs. $11.1 \%)$.

Among all the participants, 995 (60.1\%) had NAFLD, while $605(36.6 \%)$ had AO. The prevalence of AO increased from $31.7 \%$ $(n=364)$ in subjects with CACS $=0$ to $44.2 \%(n=168)$ in subjects with $0<\mathrm{CACS} \leq 100$ and $57 \%(n=73)$ in subjects with CACS $>100$ (Figure 3B). The same trend was found in men $(n$ $=234,31 \% ; n=119,39.4 \%$; and $n=60,56.6 \%$, respectively). However, in women, the highest prevalence of $\mathrm{AO}$ was noted in subjects with $0<\mathrm{CACS} \leq 100(49,62.8 \%)$. Subjects with $0<$ CACS $\leq 100$ had the highest prevalence of NAFLD compared with the other groups; this was statistically significant in the overall population and in women, but not in men (total, women, men: 258, 67.9\%; 210, 69.5\%; 48, 61.5\%) (Figure 3B).

\section{Risk for Intermediate to High CAD Risk (FRS $\geq 10 \%$ ) in Subjects With Either NAFLD or AO}

In the univariate analyses, the $\mathrm{OR}$ for $\mathrm{FRS} \geq 10 \%$ was much higher in the NAFLD group than in the AO group in men, but not in total and women. In the adjusted model, the OR of FRS $\geq 10 \%$ in subjects with NAFLD increased compared to subjects without NAFLD in the overall population and in men (Table 3A). The OR for FRS $\geq 10 \%$ was higher in subjects with AO compared with those without AO in women (Table 3A). In the multivariable analyses, after adjustment for age, DM, HTN, hyperlipidemia history, cigarette smoking, alcohol drinking, and exercise, the OR of the NAFLD and AO groups was attenuated, whereas the NAFLD group showed a relatively increased risk for $\mathrm{FRS} \geq 10 \%$ compared to that without NAFLD, and the OR was higher than that in men with $\mathrm{AO}$ as well [3.26; $95 \%$ confidence interval (CI) $2.13-4.98$ vs. 2.97 ; 95\% CI $1.91-4.62$ ] (Table 3A). However, women with AO and NAFLD consistently had an significant statistical OR for FRS $\geq 10 \%$, but OR was higher in the AO group than in the NAFLD group (Table 3A). In the Supplementary Table 1A, after adjusting BMI variable, the results still had statistical difference. The variance inflation 
TABLE 3A | Odds ratio for Framingham risk score $\geq 10 \%$ in subjects with either non-alcoholic fatty liver disease or abdominal obesity.

\begin{tabular}{|c|c|c|c|c|c|c|c|c|c|c|c|}
\hline \multirow[t]{2}{*}{ Variables } & \multirow[b]{2}{*}{$n$} & \multirow[b]{2}{*}{$(\%)$} & \multicolumn{3}{|c|}{ Model 1} & \multicolumn{3}{|c|}{ Model 2} & \multicolumn{3}{|c|}{ Model 3} \\
\hline & & & Odds ratio & $95 \% \mathrm{Cl}$ & $p$-value & Odds ratio & $95 \% \mathrm{Cl}$ & $p$ value & Odds ratio & $95 \% \mathrm{Cl}$ & $p$-value \\
\hline \multicolumn{12}{|c|}{ Total $^{\star}(n=560)$} \\
\hline NAFLD & 400 & $71.4 \%$ & 2.10 & $(1.69-2.62)$ & $<0.001$ & 3.00 & (2.28-3.95) & $<0.001$ & 3.21 & $(2.18-4.73)$ & $<0.001$ \\
\hline $\mathrm{AO}$ & 292 & $52.1 \%$ & 2.72 & (2.20-3.36) & $<0.001$ & 3.24 & $(2.41-4.36)$ & $<0.001$ & 2.92 & $(2.02-4.21)$ & $<0.001$ \\
\hline \multicolumn{12}{|c|}{ Men $(n=480)$} \\
\hline NAFLD & 341 & $71.0 \%$ & 2.69 & $(2.10-3.45)$ & $<0.001$ & 3.25 & $(2.33-4.55)$ & $<0.001$ & 3.26 & $(2.13-4.98)$ & $<0.001$ \\
\hline $\mathrm{AO}$ & 234 & $48.8 \%$ & 1.60 & (1.25-2.06) & $<0.001$ & 2.43 & (1.73-3.42) & $<0.001$ & 2.97 & $(1.91-4.62)$ & $<0.001$ \\
\hline \multicolumn{12}{|c|}{ Women $(n=80)$} \\
\hline NAFLD & 59 & $73.8 \%$ & 3.55 & $(2.08-6.07)$ & $<0.001$ & 3.37 & $(1.76-6.44)$ & $<0.001$ & 2.30 & $(1.07-4.94)$ & 0.03 \\
\hline $\mathrm{AO}$ & 58 & $72.5 \%$ & 5.43 & (3.19-9.25) & $<0.001$ & 6.41 & (3.02-13.59) & $<0.001$ & 4.77 & $(2.01-11.34)$ & $<0.001$ \\
\hline
\end{tabular}

TABLE 3B | Odds ratio for coronary artery calcification $(>0)$ in subjects with either non-alcoholic fatty liver disease or abdominal obesity.

\begin{tabular}{|c|c|c|c|c|c|c|c|c|c|c|c|}
\hline \multirow[t]{2}{*}{ Variables } & \multirow[b]{2}{*}{$n$} & \multirow[b]{2}{*}{$(\%)$} & \multicolumn{3}{|c|}{ Model 1} & \multicolumn{3}{|c|}{ Model 2} & \multicolumn{3}{|c|}{ Model 3} \\
\hline & & & Odds ratio & $95 \% \mathrm{Cl}$ & $p$-value & Odds ratio & $95 \% \mathrm{Cl}$ & $p$ value & Odds ratio & $95 \% \mathrm{Cl}$ & $p$-value \\
\hline \multicolumn{12}{|c|}{ Total $^{\star}(n=508)$} \\
\hline NAFLD & 339 & $66.7 \%$ & 1.50 & $(1.21-1.87)$ & $<0.001$ & 1.43 & $(1.12-1.83)$ & 0.004 & 1.39 & $(1.08-1.79)$ & 0.01 \\
\hline $\mathrm{AO}$ & 241 & $47.4 \%$ & 1.94 & $(1.57-2.41)$ & $<0.001$ & 1.62 & $(1.27-2.05)$ & $<0.001$ & 1.46 & $(1.14-1.87)$ & 0.003 \\
\hline \multicolumn{12}{|c|}{ Men $(n=408)$} \\
\hline NAFLD & 280 & $68.6 \%$ & 1.29 & $(1.00-1.67)$ & 0.048 & 1.39 & $(1.05-1.85)$ & 0.02 & 1.37 & $(1 / 03-1.83)$ & 0.03 \\
\hline $\mathrm{AO}$ & 179 & $43.8 \%$ & 1.74 & $(1.36-2.24)$ & $<0.001$ & 1.51 & $(1.15-1.98)$ & 0.003 & 1.35 & $(1.02-1.79)$ & 0.04 \\
\hline \multicolumn{12}{|c|}{ Women $(n=100)$} \\
\hline NAFLD & 59 & $59.0 \%$ & 1.67 & $(1.07-2.61)$ & 0.02 & 1.54 & $(0.94-2.54)$ & 0.09 & 1.47 & $(0.87-2.47)$ & 0.15 \\
\hline $\mathrm{AO}$ & 62 & $62.0 \%$ & 3.28 & $(2.08-5.17)$ & $<0.001$ & 1.97 & (1.19-3.26) & 0.01 & 1.87 & $(1.11-3.16)$ & 0.02 \\
\hline
\end{tabular}

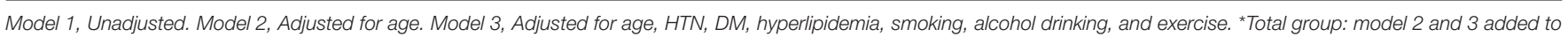
adjust for sex.

factor (VIF) for each independent variable by checking multicollinearity did not reach collinearity.

\section{Risk of CACS $>0$ in Subjects With Either NAFLD or AO}

In the univariate analyses, the OR for CACS $>0$ was much higher in the AO group than in the NAFLD group in both genders. However, in the adjusted model, the OR of CACS $>0$ in subjects with NAFLD increased compared to subjects without NAFLD in men, but not in women (Table 3B). The OR for CACS $>0$ was higher in subjects with AO compared with subjects without AO overall (Table 3B). In the multivariate analyses, after adjustment for age, DM, HTN, hyperlipidemia history, cigarette smoking, alcohol drinking, and exercise, the OR of the NAFLD and AO groups was attenuated, whereas the NAFLD group showed a relatively increased risk for CACS $>0$ compared to that without NAFLD, and the OR was higher than that in men with $\mathrm{AO}$ as well $[1.37 ; 95 \%$ confidence interval (CI) $1.03-1.83$ vs. 1.35; 95\% CI 1.02-1.79] (Table 3B). However, women with AO consistently had an increased OR for CACS $>0$, while subjects with NAFLD showed a non-significantly increased OR for CACS $>0$ (Table 3B). In the Supplementary Table 1B, after adjusting $\mathrm{BMI}$ variable, the results became no statistical difference. The VIF for each independent variable by checking multi-collinearity did not reach collinearity.

\section{Risk for Intermediate to High CAD Risk (FRS $\geq 10 \%$ ) in Groups by NAFLD and AO Status}

Table $4 \mathrm{~A}$ shows the association of FRS $\geq 10 \%$ with NAFLD and AO. In the univariate analysis, the OR for FRS $\geq 10 \%$ was highest in the group with both abnormalities, second highest in the group with AO only, and third highest in the group with NAFLD only. In the age-adjusted model, the OR for FRS $\geq 10 \%$ was the highest in the overall population and in men, but not in women, the AO-only group had a higher risk of FRS $\geq 10 \%$ than the NAFLD-only groups. In the multivariate analyses, the OR for FRS $\geq 10 \%$ was the highest in the group with both abnormalities (men: 5.86; 95\% CI 3.37-10.20; women: 6.31; 95\% CI 2.08-19.10). The group with NAFLD only and with both abnormalities showed a significantly increased OR for $\mathrm{FRS} \geq 10 \%$ in men $(2.21$; $95 \%$ CI $1.32-10.20$ and 5.86; 95\% CI 3.37-10.20) (Table 4A). In contrast, in the NAFLD-only group, the risk of FRS $\geq 10 \%$ increased and remained statistically significant. In women, adjustment for factors increased the OR, and the OR for FRS $\geq 10 \%$ was significantly increased 
TABLE 4A | Odds ratio for Framingham risk score $\geq 10 \%$ (intermediate to high cardiovascular disease risk) in groups divided by non-alcoholic fatty liver disease and abdominal obesity status.

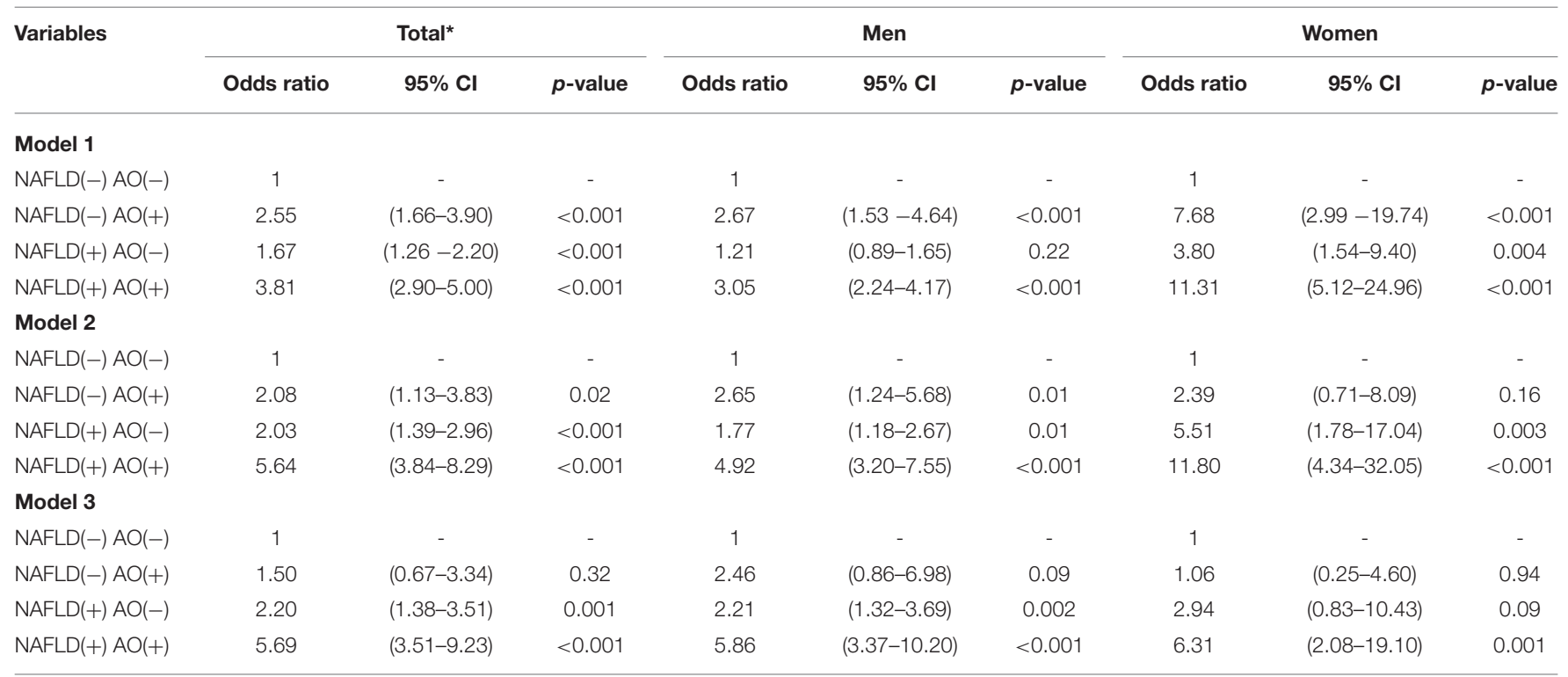

TABLE 4B | Odds ratio for coronary artery calcification in groups divided by nonalcoholic fatty liver disease and abdominal obesity status.

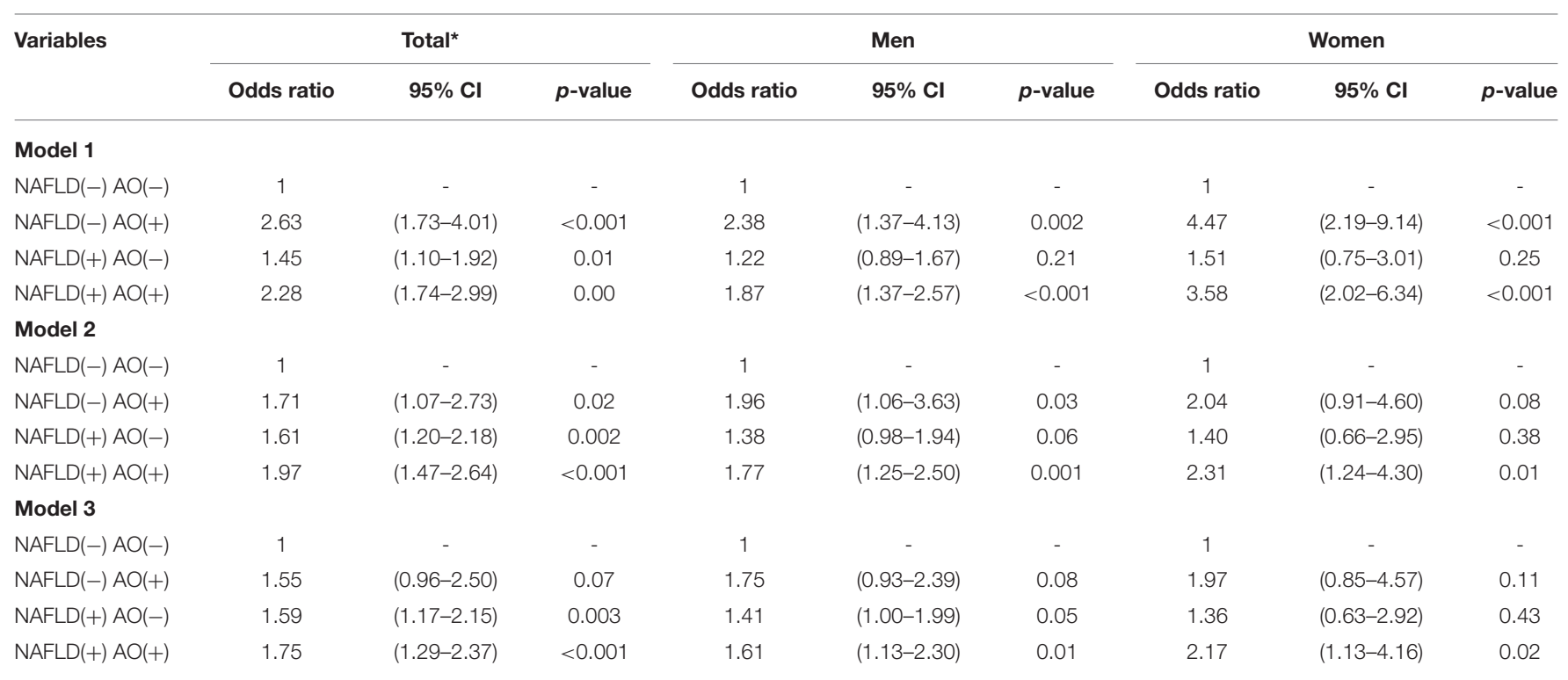

Model 1, Unadjusted. Model 2, Adjusted for age. Model 3, Adjusted for age, HTN, DM, hyperlipidemia, smoking, alcohol drinking, and exercise. *Total group: model 2 and 3 added to adjust for sex. Abbreviations as list in Table 1.

only in subjects with both NAFLD and AO (Table 4A). In the Supplementary Table 2A, after adjusting BMI variable, the results became no statistical difference. The VIF for each independent variable by checking multi-collinearity did not reach collinearity.

\section{Risk of CACS $>0$ in Groups by NAFLD and AO Status}

Table 4B shows the association of CACS $>0$ with NAFLD and $\mathrm{AO}$. In the univariate analyses, the OR of CACS $>0$ was highest in the pure AO group, second highest in the group with both abnormalities, and third highest in the pure NAFLD group. In the age-adjusted model, the OR for CACS $>0$ was highest in the total population and in women, In contrast, among men, the risk of CACS $>0$ was higher in the pure AO group than in the pure NAFLD group. In multivariate analysis, the OR of CACS $>0$ was the highest among the groups with both abnormalities (men: 1.61 ; 95\% CI 1.13-2.30; women: 2.17 ; 95\% CI 1.13-4.16). The groups with NAFLD only and with both abnormalities showed a significantly increased OR for CACS $>0$ 
in men $(1.41 ; 95 \%$ CI $1.05-1.99$ and $1.61 ; 95 \%$ CI $1.13-2.30)$ (Table 4B). Although the risk of CACS $>0$ was increased in the NAFLD-only group, this was attenuated in the AO-only group and remained statistically significant. In women, adjustment for factors attenuated the OR, with significantly increased OR for CACS $>0$ only in subjects with both NAFLD and AO (Table 4B). In the Supplementary Table 2B, after adjusting BMI variable, the results became no statistical difference. The VIF for each independent variable by checking multi-collinearity did not reach collinearity.

\section{DISCUSSION}

Similar to previous studies $(29,31,37,38)$, our cross-sectional study was performed in a health-screening cohort and aimed to determine the relationship between prevalent NAFLD/AO and subclinical atherosclerosis/CAD risk. However, unique to our data was the finding that men with NAFLD have a significantly increased risk of CACS $>0$ and FRS $\geq 10 \%$ compared to those with $\mathrm{AO}$, whereas women with $\mathrm{AO}$ had a significantly increased risk for CACS $>0$ and FRS $\geq 10 \%$. In the Bonferroni posthoc analysis, the mean $\ln (\mathrm{CACS}+1)$ or age/sex-adjusted mean $\ln (\mathrm{CACS}+1)$ was highest in subjects with AO-only group and lowest in subjects without any abnormality. The overall population with AO and NAFLD was significantly associated with CACS $>0$ and FRS $\geq 10 \%$. In summary, our results suggest that NAFLD is more closely associated with CACS $>$ 0 and FRS $\geq 10 \%$ than $\mathrm{AO}$ in men, whereas $\mathrm{AO}$ is more closely associated with CACS $>0$ and FRS $\geq 10 \%$ than NAFLD in women.

NAFLD is defined as the accumulation of more than $5 \%$ fat in hepatocytes in individuals whose alcohol intake is lower than $20 \mathrm{~g} / \mathrm{d}(20-23)$. Although NAFLD is known as a hepatic manifestation of IR or MetS, several clinical studies have observed an association of NAFLD with CAC, independent of risk factors for cardiovascular disease such as IR, metabolic factors, and visceral adiposity tissue (37, 3942). In support of the present findings in men, NAFLD, measured by magnetic resonance spectroscopy, was superior to visceral obesity, measured by magnetic resonance tomography, in determining increased carotid intima-media thickness, an estimate of early atherosclerosis, in subjects with prediabetes (43). In addition, studies have pointed out that genetically-driven NAFLD-related genes such as PNPLA3 and TM6SF2 genes are associated with increased liver fat content and progression to $\mathrm{NASH}$ and cirrhosis. However, these alleles are also unexpectedly associated with apparent protection from cardiovascular disease. Early detection of gene mutations will help the treatment of hepatic and extrahepatic diseases in different directions (44).

A previous study by Lee et al. (29) showed that AO measured via WHR was highly associated with CAC across the body in middle-aged Korean men. Low HC (decreased gluteo-femoral fat mass) is not only associated with NAFLD and AO, but is now also established as an important and independent risk factor of cardiometabolic diseases (17). Joo et al. (18) mentioned CT-measured WC using a fully automated body segmentation algorithm was closely correlated with manually-measured WC. Seimon et al. (19) found that WC was measured at the midpoint between the lowest rib and the iliac crest $\left(\mathrm{WC}_{\mathrm{mid}}\right)$ and the narrowest point of the torso $\left(\mathrm{WC}_{\text {narrow }}\right)$ were gold-standard measurements which provided accurate estimations of visceral adipose tissue (VAT), as determined by MRI (Correlation $r=$ 0.581 and $0.563 ; p<0.001$ for all), especially for postmenopausal women with obesity. Our study also took the position of $\mathrm{WC}_{\text {mid }}$ for measurement, which has a correct correlation with VAT. Our results showed that $\mathrm{AO}$ measured via $\mathrm{WC}$ was strongly correlated with CAC in both genders. WC is an easier, convenience, and correct measurement of $\mathrm{AO}$ than $\mathrm{HC}$ or WHR, and based on our data, it can be considered an independent risk factor for CAC $(16,18,19,45)$.

Because FRS is easily calculated in the office setting, routine calculation of the FRS in NAFLD patients may be beneficial in identifying those NAFLD patients at highest risk of $\mathrm{CHD}$ outcomes (31). Treeprasertsuk et al. (31) suggested that a cutpoint of 11 for women and 6 for men is the most sensitive cut-point for predicting CHD events. In this previous study, in these patients with NAFLD, the estimated 10-year CHD risk derived from the FRS (12.6\% in men and 9.6\% in women), respectively. For men with NAFLD, FRS is more sensitive than women, and patients with scores at or above these values may necessitate a more aggressive cardiac follow-up (31). In our study, we found a similar significant correlation with gender, and there was proportionally higher risk of CACS $>0$ and FRS $\geq 10 \%$ among men with NAFLD than among women.

In this study, men and women with high WC (i.e., $>90$ and $80 \mathrm{~cm}$, respectively) and without NAFLD were generally older and had higher blood pressure and fasting plasma glucose than subjects with NAFLD and without AO. Other studies have closely associated WC to hypertension and IR, which are wellknown causes for CAC (46-48); WC was mentioned by Cassidy et al. (49) to be associated with the progression of subclinical coronary atherosclerosis. Our study results suggest that CACS was highest in men and women with $\mathrm{AO}$ only. After adjusting for known CAD risk factors such as age, chronic diseases, and lifestyle habits, patients with both NAFLD and AO had a synergistically increased risk for subclinical atherosclerosis and CAD risk. Moreover, after making the same adjustments, men with NAFLD only retained a significantly higher risk for CACS $>0$ and $\mathrm{FRS} \geq 10 \%$ than those with AO only. In contrast, women with AO only had a significantly higher risk for CACS $>0$ and FRS $\geq 10 \%$ than those with NAFLD only. However, the higher risk for CAC and CAD risk in men with NAFLD only could possibly be attributed to higher prevalence of NAFLD in men (50). In a systematic review and meta-analysis, Balakrishnan et al. (50) found that women had a lower risk of NAFLD compared to men. From previous studies, it is understood that gender is one of the main determinants of body fat distribution $(51,52)$. Previous data has shown that visceral fat increases are greater in women than in men (51), which could be the one of the reasons for the higher risk for CAC and CAD risk in women with AO only. Our findings were consistent with those of a study by VanWagner et al. (38) performed in 2,424 participants, which suggested the importance of $\mathrm{AO}$ in the association of CAC and NAFLD Our results also support those of Lee et al. (29) which found that NAFLD was highly associated with CAC across the body in men. 
Fat accumulation in hepatocytes and in the abdominal area are more closely associated with visceral adipose tissue (VAT) $(45,53)$. Increased VAT causes increased secretion of proinflammatory cytokines and adipokines, thus releasing free fatty acids into the body circulation system, which plays a role in the pathogenesis of NAFLD and AO $(54,55)$. Therefore, visceral fat accumulation might be a mediator linking NAFLD and AO to $\operatorname{CAD}(45,54)$. Previous data have shown that visceral fat increases over $200 \%$ in men and $400 \%$ in women between the $3 \mathrm{rd}$ and 7 th decades, owing to a shift from peripheral to central fat patterning. These studies have attempted to identify hormones that may be responsible for this shift $(51,52)$. These hormone or inflammation factors might play a role in the gender-based differences we found in our study.

Previous researchers seldom discussed the impact of BMI and excluded it in the multivariate analysis (29). The NAFLD/AO effect became non-significant after adjusting BMI in this study. This finding appeared not to be the impact of collinearity. We inferred BMI might confound the NAFLD/AO effect because $\mathrm{BMI}, \mathrm{AO}$, and NAFLD are all related to the inflammation of the body (29, 54-62). However, note a significant association between FRS and the NAFLD/AO (Supplementary Table) after adjusting BMI. We encouraged more future research to present more evidence to support this argument.

Previously, AO was consistently associated with NAFLD in $60-95 \%$ of cases, and AO assessed by WHR or WC was strongly associated with the prevalence of $\operatorname{NAFLD}(63,64)$. AO was highly correlated with major cardiometabolic risk factors and established CVD, DM, or FRS $\geqq 10 \%$, suggesting it may be an easily measured surrogate for people at increased risk of future cardiovascular clinical events who may benefit from further assessment and intervention, especially for women (49). A casecontrol study recruiting 102 patients aged $\geqq 60$ years in Egypt showed that WC is a strong risk factor for hypertension and intermediate to high FRS score in Egyptian elderly women and not in men (65). Our study is consistent with these previous findings; In the absence of evidence of NAFLD, high WC may be an independent risk factor for CAD in women.

The strength of this study was to provide two methods to assess CAD risk, including CACS and FRS. The findings showed that NAFLD is more closely associated with CACS $>0$ and FRS $\geq 10 \%$ than $\mathrm{AO}$ in men, whereas AO is more closely associated with CACS $>0$ and FRS $\geq 10 \%$ than NAFLD in women. NAFLD and AO could be considered independent determinants of CACS by gender.

\section{LIMITATIONS}

Our study has some potential limitations. First, our results might have varied according to the definition of WC (modified NCEP-ATP III for Taiwanese) $(35,36)$. It is unclear whether these results apply to races other than Taiwanese and to other East Asians. Second, a higher prevalence rate was found in Taiwan (11.5-52\%) (23). It was as high as $80 \%$ in participants who were overweight or obese (66). In this study, the mean BMI was overweight, which resulted in higher prevalence of
NAFLD (60.1\%).This could have affected the relationship we found between NAFLD and CACS/FRS. Third, there were more men than women enrolled in the study, and the age of women were older than age of me in four groups, which may also cause differences in results [In Table 2, age-adjusted mean Ln $(\mathrm{CACS}+1)$ values differ from age- and sex-adjusted mean Ln $(\mathrm{CACS}+1)$ values)]. Ultimately, large-scale, prospective trials with a balanced proportion of men and women are needed to affirm our findings. Fourth, we also need to acknowledge the lack of assessment of proinflammatory cytokines, adipokines, or hormones (such as hs-CRP, IL-1, IL-6, or estrogen) (67), gene mutation (44), and hip circumference (17) in the current study. We were unable to further strengthen the role of these factors s in mediating atherosclerotic pathophysiology underlying excessive visceral adiposity. Fifth, determining alcohol intake history by self-questioning alone may introduce bias into the study. Sixth, US detects only moderate/severe hepatic steatosis. We use the double-blind progress of the operating physician to confirm the examination results, but in the future, we still need to use CT or MRI for liver fat confirmation $(18,19,43)$. Finally, this study was cross-sectional design that did not allowto infer causality from the associations described. These subjects were from the Physical Examination Center to participate in this cardiovascular health survey, not from the clinical outpatient departments, which can reduce the selection error caused by existing diseases. However, the sample from a single tertiary medical center might still be due to differences in health habits and health concepts that caused Neyman bias. These limitations may be the reason why the ORs in Table 3 seems to be exaggerated in this study.

\section{CONCLUSION}

In this health-screening population, Men with NAFLD only had a significantly higher risk of CAC and CAD than men with AO only, whereas this was higher in women with AO only than in women with NAFLD only after adjusting for age, chronic diseases, and lifestyle habits. Limited information was known about the exact gender-specific roles of NAFLD and AO as risk factors for CAD in previous studies. With the data from our study, we hope to determine the underlying pathogenesis related to the association of NAFLD and AO with CAD, and to establish effective lifestyle and drug treatment to prevent and reduce the occurrence of these diseases, ultimately reducing the risk of CAD in both men and women.

\section{DATA AVAILABILITY STATEMENT}

The raw data supporting the conclusions of this article will be made available by the authors, without undue reservation.

\section{ETHICS STATEMENT}

The study protocol was evaluated and approved by the Human Research Ethics Committee of Mackay Memorial Hospital (project research number 18MMHIS137, 15 Oct 2018) and are in accordance with the Helsinki Declaration of 1975. Written 
informed consent for participation was not required for this study in accordance with the national legislation and the institutional requirements.

\section{AUTHOR CONTRIBUTIONS}

M-TT conceived and designed this study, performed cyroablation procedures, analyzed the data, contributed to data collection, and wrote the manuscript. J-YC carried subject's

\section{REFERENCES}

1. Mendis S, Puska P, Norrving B. Global Atlas on Cardiovascular Disease Prevention And Control. Geneva: World Health Organization in collaboration with the World Heart Federation and World Stroke Organization (2011).

2. Wexler L, Brundage B, Crouse J, Detrano R, Fuster V, Maddahi J, et al. Coronary artery calcification: pathophysiology, epidemiology, imaging methods, and clinical implications. a statement for health professionals from the American heart association writing group. Circulation. (1996) 94:117592. doi: 10.1161/01.CIR.94.5.1175

3. Budoff MJ, Achenbach S, Blumenthal RS, Carr JJ, Goldin JG, Greenland P, et al. American heart association committee on cardiovascular imaging and intervention; American heart association council on cardiovascular radiology and intervention; American heart association committee on cardiac imaging, council on clinical cardiology. assessment of coronary artery disease by cardiac computed tomography: a scientific statement from the American heart association committee on cardiovascular imaging and intervention, council on cardiovascular radiology and intervention, and committee on cardiac imaging, council on clinical cardiology. Circulation. (2006) 114:176191. doi: 10.1161/CIRCULATIONAHA.106.178458

4. D'Agostino RB, Vasan RS, Pencina MJ, Wolf PA, Cobain M, Massaro JM, et al. General cardiovascular risk profile for use in primary care: the framingham heart study. Circulation. (2008) 117:743-53. doi: 10.1161/CIRCULATIONAHA.107.699579

5. Yeh JS, Kao YT, Lin FY, Shih CM, Tsao NW, Chan CS, et al. Combined framingham risk score and coronary artery calcium score predict subclinical coronary plaque assessed by coronary computed tomography angiogram in asymptomatic Taiwanese population. Acta Cardiol Sin. (2013) 29:429-35.

6. Greenland P, LaBree L, Azen SP, Doherty TM, Detrano RC. Coronary artery calcium score combined with framingham score for risk prediction in asymptomatic individuals. JAMA. (2004) 291:210-5. doi: 10.1001/jama.291.2.210

7. Dahlén EM, Bjarnegård N, Länne T, Nystrom FH, Ostgren CJ. Sagittal abdominal diameter is a more independent measure compared with waist circumference to predict arterial stiffness in subjects with type 2 diabetesa prospective observational cohort study. Cardiovasc Diabetol. (2013) 12:55. doi: 10.1186/1475-2840-12-55

8. Ren C, Zhang J, Xu Y, Xu B, Sun W, Sun J, et al. Association between carotid intima-media thickness and index of central fat distribution in middle-aged and elderly Chinese. Cardiovasc Diabetol. (2014) 13:139. doi: 10.1186/s12933-014-0139-2

9. Hubert HB, Feinleib M, McNamara PM, Castelli WP. Obesity as an independent risk factor for cardiovascular disease: a 26-year follow-up of participants in the Framingham heart study. Circulation. (1983) 67:96877. doi: 10.1161/01.CIR.67.5.968

10. Osawa K, Miyoshi T, Koyama Y, Sato S, Akagi N, Morimitsu Y, et al. Differential association of visceral adipose tissue with coronary plaque characteristics in patients with and without diabetes mellitus. Cardiovasc Diabetol. (2014) 13:61. doi: 10.1186/1475-2840-13-61

11. Lakka TA, Lakka HM, Salonen R, Kaplan GA, Salonen JT. Abdominal obesity is associated with accelerated progression of carotid atherosclerosis in men. Atherosclerosis. (2001) 154:497-504. doi: 10.1016/S0021-9150(00) 00514-1 recruitment and data interpretation and performed cryoablation procedures. All authors contributed to the article and approved the submitted version.

\section{SUPPLEMENTARY MATERIAL}

The Supplementary Material for this article can be found online at: https://www.frontiersin.org/articles/10.3389/fcvm. 2022.803967/full\#supplementary-material

12. Rexrode KM, Carey VJ, Hennekens CH, Walters EE, Colditz GA, Stampfer $\mathrm{MJ}$, et al. Abdominal adiposity and coronary heart disease in women. JAMA. (1998) 280:1843-8. doi: 10.1001/jama.280.21.1843

13. Mathieu P, Pibarot P, Larose E, Poirier P, Marette A, Després JP. Visceral obesity and the heart. Int J Biochem Cell Biol. (2008) 40:82136. doi: 10.1016/j.biocel.2007.12.001

14. Yu JH, Yim SH, Yu SH, Lee JY, Kim JD, Seo MH, et al. The relationship of body composition and coronary artery calcification in apparently healthy Korean adults. Endocrinol Metab. (2013) 28:33-40. doi: 10.3803/EnM.2013.28.1.33

15. Stefan N, Birkenfeld AL, Schulze MB. Global pandemics interconnected - obesity, impaired metabolic health and COVID-19. Nat Rev Endocrinol. (2021) 17:135-49. doi: 10.1038/s41574-020-00462-1

16. Park J, Lee ES, Lee DY, Kim J, Park SE, Park CY, et al. Waist circumference as a marker of obesity is more predictive of coronary artery calcification than body mass index in apparently healthy Korean adults: the kangbuk samsung health study. Endocrinol Metab. (2016) 31:559-66. doi: 10.3803/EnM.2016.31.4.559

17. Stefan N. Causes, consequences, and treatment of metabolically unhealthy fat distribution. Lancet Diabetes Endocrinol. (2020) 8:616-27. doi: 10.1016/S2213-8587(20)30110-8

18. Joo I, Kwak MS, Park DH, Yoon SH. Fully automated waist circumference measurement on abdominal CT: Comparison with manual measurements and potential value for identifying overweight and obesity as an adjunct output of CT scan. PLoS ONE. (2021) 16:e0254704. doi: 10.1371/journal.pone.0254704

19. Seimon RV, Wild-Taylor AL, Gibson AA, Harper C, McClintock S Fernando HA, et al. Less waste on waist measurements: determination of optimal waist circumference measurement site to predict visceral adipose tissue in postmenopausal women with obesity. Nutrients. (2018) 10:239. doi: 10.3390/nu10020239

20. Samji NS, Verma R, Satapathy SK. Magnitude of nonalcoholic fatty liver disease: western perspective. J Clin Exp Hepatol. (2019) 9:497505. doi: 10.1016/j.jceh.2019.05.001

21. Farrell GC. Non-alcoholic steatohepatitis: what is it, and why is it important in the asia-pacific region? J Gastroenterol Hepatol. (2003) 18:12438. doi: 10.1046/j.1440-1746.2003.02989.x

22. Chitturi S, Farrell GC, George J. Non-alcoholic steatohepatitis in the asia-pacific region: future shock? J Gastroenterol Hepatol. (2004) 19:36874. doi: 10.1111/j.1440-1746.2003.03252.x

23. Hsu CS, Kao JH. An update on non-alcoholic fatty liver disease and nonalcoholic steatohepatitis in Asia. Expert Rev Gastroenterol Hepatol. (2017) 11:759-72. doi: 10.1080/17474124.2017.1342535

24. Marchesini G, Brizi M, Bianchi G, Tomassetti S, Bugianesi E, Lenzi M, et al. Nonalcoholic fatty liver disease: a feature of the metabolic syndrome. Diabetes. (2001) 50:1844-50. doi: 10.2337/diabetes.50.8.1844

25. Fraser A, Longnecker MP, Lawlor DA. Prevalence of elevated alanine aminotransferase among US adolescents and associated factors: NHANES 1999-2004. Gastroenterology. (2007) 133:181420. doi: 10.1053/j.gastro.2007.08.077

26. Villanova N, Moscatiello S, Ramilli S, Bugianesi E, Magalotti D, Vanni E, et al. Endothelial dysfunction and cardiovascular risk profile in nonalcoholic fatty liver disease. Hepatology. (2005) 42:473-80. doi: 10.1002/hep.20781

27. Fargion S, Porzio M, Fracanzani AL. Nonalcoholic fatty liver disease and vascular disease: state-of-the-art. World J Gastroenterol. (2014) 20:1330624. doi: 10.3748/wjg.v20.i37.13306 
28. Puchner SB, Lu MT, Mayrhofer T, Liu T, Pursnani A, Ghoshhajra BB, et al. High-risk coronary plaque at coronary CT angiography is associated with nonalcoholic fatty liver disease, independent of coronary plaque and stenosis burden: results from the ROMICAT II trial. Radiology. (2015) 274:693701. doi: 10.1148/radiol.14140933

29. Lee MK, Park HJ, Jeon WS, Park SE, Park CY, Lee WY, et al. Higher association of coronary artery calcification with non-alcoholic fatty liver disease than with abdominal obesity in middle-aged Korean men: the Kangbuk samsung health study. Cardiovasc Diabetol. (2015) 14:88. doi: 10.1186/s12933-015-0253-9

30. Ioannou GN, Weiss NS, Boyko EJ, Mozaffarian D, Lee SP. Elevated serum alanine aminotransferase activity and calculated risk of coronary heart disease in the United States. Hepatology. (2006) 43:1145-51. doi: 10.1002/hep.21171

31. Treeprasertsuk S, Leverage S, Adams LA, Lindor KD, St Sauver J, Angulo P. The Framingham risk score and heart disease in nonalcoholic fatty liver disease. Liver Int. (2012) 32:945-50. doi: 10.1111/j.1478-3231.2011.02753.x

32. Yun CH, Lin TY, Wu YJ, Liu CC, Kuo JY, Yeh HI, et al. Pericardial and thoracic peri-aortic adipose tissues contribute to systemic inflammation and calcified coronary atherosclerosis independent of body fat composition, anthropometric measures and traditional cardiovascular risks. Eur J Radiol. (2012) 81:749-56. doi: 10.1016/j.ejrad.2011.01.035

33. Fan JG, Jia JD, Li YM, Wang BY, Lu LG, Shi JP, et al. Guidelines for the diagnosis and management of nonalcoholic fatty liver disease: update 2010: (published in Chinese on Chinese Journal of Hepatology 18:163-166). J Dig Dis. (2011) 12:38-44. doi: 10.1111/j.1751-2980.2010.00476.x

34. Farrell GC, Chitturi S, Lau GK, Sollano JD. Asia-Pacific Working Party on NAFLD. Guidelines for the assessment and management of non-alcoholic fatty liver disease in the AsiaPacific region: executive summary. J Gastroenterol Hepatol. (2007) 22:775-7. doi: 10.1111/j.1440-1746.2007.05002.x

35. Lin CC, Liu CS, Lai MM, Li CI, Chen CC, Chang PC, et al. Metabolic syndrome in a Taiwanese metropolitan adult population. BMC Public Health. (2007) 7:239-43. doi: 10.1186/1471-2458-7-239

36. National Cholesterol Education Program (NCEP) Expert Panel on Detection, Evaluation, and Treatment of High Blood Cholesterol in Adults (Adult Treatment Panel III). Third report of the national cholesterol education program (NCEP) expert panel on detection, evaluation, and treatment of high blood cholesterol in adults (Adult Treatment Panel III) final report. Circulation. (2002) 106:3143-421. doi: 10.1161/circ.106. 25.3143

37. Kim D, Choi SY, Park EH, Lee W, Kang JH, Kim W, et al. Nonalcoholic fatty liver disease is associated with coronary artery calcification. Hepatology. (2012) 56:605-13. doi: 10.1002/hep.25593

38. VanWagner LB, Ning H, Lewis CE, Shay CM, Wilkins J, Carr JJ, et al. Associations between nonalcoholic fatty liver disease and subclinical atherosclerosis in middle-aged adults: the coronary artery risk development in young adults study. Atherosclerosis. (2014) 235:599-605. doi: 10.1016/j.atherosclerosis.2014.05.962

39. Chen $\mathrm{CH}$, Nien CK, Yang CC, Yeh YH. Association between nonalcoholic fatty liver disease and coronary artery calcification. Dig Dis Sci. (2010) 55:1752-60. doi: 10.1007/s10620-009-0935-9

40. Sung KC, Wild SH, Kwag HJ, Byrne CD. Fatty liver, insulin resistance, and features of metabolic syndrome: relationships with coronary artery calcium in 10,153 people. Diabetes Care. (2012) 35:2359-64. doi: 10.2337/dc12-0515

41. Liu J, Musani SK, Bidulescu A, Carr JJ, Wilson JG, Taylor HA, et al. Fatty liver, abdominal adipose tissue and atherosclerotic calcification in African Americans: the jackson heart study. Atherosclerosis. (2012) 224:5215. doi: 10.1016/j.atherosclerosis.2012.07.042

42. Chhabra R, O’Keefe JH, Patil H, O’Keefe E, Thompson RC, Ansari $\mathrm{S}$, et al. Association of coronary artery calcification with hepatic steatosis in asymptomatic individuals. Mayo Clin Proc. (2013) 88:1259-65. doi: 10.1016/j.mayocp.2013.06.025

43. Stefan N, Fritsche A, Schick F, Häring HU. Phenotypes of prediabetes and stratification of cardiometabolic risk. Lancet Diabetes Endocrinol. (2016) 4:789-98. doi: 10.1016/S2213-8587(16)00082-6

44. Stefan N, Häring HU, Cusi K. Non-alcoholic fatty liver disease: causes, diagnosis, cardiometabolic consequences, and treatment strategies. Lancet Diabetes Endocrinol. (2019) 7:313-24. doi: 10.1016/S2213-8587(18)30154-2
45. Bose S, Krishnamoorthy P, Varanasi A, Nair J, Schutta M, Braunstein S, et al. Measurement of waist circumference predicts coronary atherosclerosis beyond plasma adipokines. Obesity. (2013) 21:E118-23. doi: 10.1002/oby.20086

46. Snell-Bergeon JK, Budoff MJ, Hokanson JE. Vascular calcification in diabetes: mechanisms and implications. Curr Diab Rep. (2013) 13:391402. doi: 10.1007/s11892-013-0379-7

47. Lara M, Bustos P, Amigo H, Silva C, Rona RJ. Is waist circumference a better predictor of blood pressure, insulin resistance and blood lipids than body mass index in young Chilean adults? BMC Public Health. (2012) 12:638. doi: 10.1186/1471-2458-12-638

48. Poirier P, Lemieux I, Mauriège P, Dewailly E, Blanchet C, Bergeron J, et al. Impact of waist circumference on the relationship between blood pressure and insulin: the Quebec Health Survey. Hypertension. (2005) 45:3637. doi: 10.1161/01.HYP.0000155463.90018.dc

49. Cassidy AE, Bielak LF, Zhou Y, Sheedy PF2nd, Turner ST, Breen JF, et al. Progression of subclinical coronary atherosclerosis: does obesity make a difference? Circulation. (2005) 111:187782. doi: 10.1161/01.CIR.0000161820.40494.5D

50. Balakrishnan M, Patel P, Dunn-Valadez S, Dao C, Khan V, Ali H, et al. Women have a lower risk of nonalcoholic fatty liver disease but a higher risk of progression vs men: a systematic review and meta-analysis. Clin Gastroenterol Hepatol. (2021) 19:61-71. doi: 10.1016/j.cgh.2020.04.067

51. Hunter GR, Gower BA, Kane BL. Age related shift in visceral fat. Int J Body Compos Res. (2010) 8:103-8.

52. Lim U, Ernst T, Buchthal SD, Latch M, Albright CL, Wilkens LR, et al. Asian women have greater abdominal and visceral adiposity than Caucasian women with similar body mass index. Nutr Diabetes. (2011) 1:e6. doi: 10.1038/nutd.2011.2

53. Thamer C, Machann J, Haap M, Stefan N, Heller E, Schnödt B, et al. Intrahepatic lipids are predicted by visceral adipose tissue mass in healthy subjects. Diabetes Care. (2004) 27:2726-9. doi: 10.2337/diacare.27.11.2726

54. Silverman JF, O'Brien KF, Long S, Leggett N, Khazanie PG, Pories WJ, et al. Liver pathology in morbidly obese patients with and without diabetes. $A m J$ Gastroenterol. (1990) 85:1349-55.

55. Milić S, Lulić D, Štimac D. Non-alcoholic fatty liver disease and obesity: biochemical, metabolic and clinical presentations. World J Gastroenterol. (2014) 20:9330-7. doi: 10.3748/wjg.v20.i28.9330

56. Ellulu MS, Patimah I, Khaza'ai H, Rahmat A, Abed Y. Obesity and inflammation: the linking mechanism and the complications. Arch Med Sci. (2017) 13:851-63. doi: 10.5114/aoms.2016.58928

57. Wilkins J, Ghosh P, Vivar J, Chakraborty B, Ghosh S. Exploring the associations between systemic inflammation, obesity and healthy days: a health-related quality of life (HRQOL) analysis of NHANES 2005-2008. BMC Obes. (2018) 5:21. doi: 10.1186/s40608-018-0196-2

58. Booth ML, Hunter C, Gore CJ, Bauman A, Owen N. The relationship between body mass index and waist circumference: implications for estimates of the population prevalence of overweight. Int J Obes Relat Metab Disord. (2000) 24:1058-61. doi: 10.1038/sj.ijo.0801359

59. Chinedu SN, Ogunlana OO, Azuh DE, Iweala EE, Afolabi IS, Uhuegbu CC, et al. Correlation between body mass index and waist circumference in nigerian adults: implication as indicators of health status. J Public Health Res. (2013) 2:e16. doi: 10.4081/jphr.2013.e16

60. Gierach M, Gierach J, Ewertowska M, Arndt A, Junik R. Correlation between body mass index and waist circumference in patients with metabolic syndrome. ISRN Endocrinol. (2014) 2014:514589. doi: 10.1155/2014/514589

61. Fan R, Wang J, Du J. Association between body mass index and fatty liver risk: a dose-response analysis. Sci Rep. (2018) 8:15273. doi: 10.1038/s41598-018-33419-6

62. Loomis AK, Kabadi S, Preiss D, Hyde C, Bonato V, St Louis M, et al. Body mass index and risk of nonalcoholic fatty liver disease: two electronic health record prospective studies. J Clin Endocrinol Metab. (2016) 101:94552. doi: 10.1210/jc.2015-3444

63. Zheng RD, Chen ZR, Chen JN, Lu YH, Chen J. Role of body mass index, waist-to-height and waist-to-hip ratio in prediction of nonalcoholic fatty liver disease. Gastroenterol Res Pract. (2012) 2012:362147. doi: $10.1155 / 2012 / 362147$ 
64. Lee J, Cho YK, Kang YM, Kim HS, Jung CH, Kim HK, et al. The impact of NAFLD and waist circumference changes on diabetes development in prediabetes subjects. Sci Rep. (2019) 9:17258. doi: 10.1038/s41598-019-53947-z

65. Tawfik HM. Waist height ratio and waist circumference in relation to hypertension, Framingham risk score in hospitalized elderly Egyptians. Egypt Heart J. (2018) 70:213-16. doi: 10.1016/j.ehj.2017. 12.008

66. Hsiao TJ, Chen JC, Wang JD. Insulin resistance and ferritin as major determinants of nonalcoholic fatty liver disease in apparently healthy obese patients. Int $J$ Obes Relat Metab Disord. (2004) 28:167-72. doi: 10.1038/sj.ijo.080 2519

67. Ridker PM. From C-Reactive protein to interleukin-6 to interleukin1: moving upstream to identify novel targets for atheroprotection. Circ Res. (2016) 118:145-56. doi: 10.1161/CIRCRESAHA.115.3 06656
Conflict of Interest: The authors declare that the research was conducted in the absence of any commercial or financial relationships that could be construed as a potential conflict of interest.

Publisher's Note: All claims expressed in this article are solely those of the authors and do not necessarily represent those of their affiliated organizations, or those of the publisher, the editors and the reviewers. Any product that may be evaluated in this article, or claim that may be made by its manufacturer, is not guaranteed or endorsed by the publisher.

Copyright (C) 2022 Tsou and Chen. This is an open-access article distributed under the terms of the Creative Commons Attribution License (CC BY). The use, distribution or reproduction in other forums is permitted, provided the original author(s) and the copyright owner(s) are credited and that the original publication in this journal is cited, in accordance with accepted academic practice. No use, distribution or reproduction is permitted which does not comply with these terms. 